\section{EAACI-Jahrestagung, Berlin 2001} Wie die Mutter, so das Kind?

\author{
Die Weichen für eine spätere Allergie-Karriere werden vielleicht \\ schon im Mutterleib gestellt. Sensibilisierungen in utero scheinen \\ möglich zu sein. Wie solche immunologischen Interaktionen \\ zwischen Mutter und Kind ablaufen könnten, diskutierten Forscher \\ beim Kongress der European Academy of Allergology and Clinical \\ Immunology (EAACI).
} ie Suche nach Genen, die für die
Entstehung allergischer Erkran-
kungen verantwortlich sein können,
muss nicht nur eine Fülle genetischer
Varianten, sondern auch die Zusam-
mensetzung der Studienkollektive be-
rücksichtigen. Darauf wies Renate Ni-
ckel, derzeit Baltimore, USA, in ihrem
Eingangsreferat „Aspekte der geneti-
schen Prädisposition von Atopie und
Asthma“ hin. Die in 14 Ländern durch-
geführte ISAAC-Studie hatte sehr un-
terschiedliche ethnische Zusammenset-
zungen der Kollektive ergeben. Dies

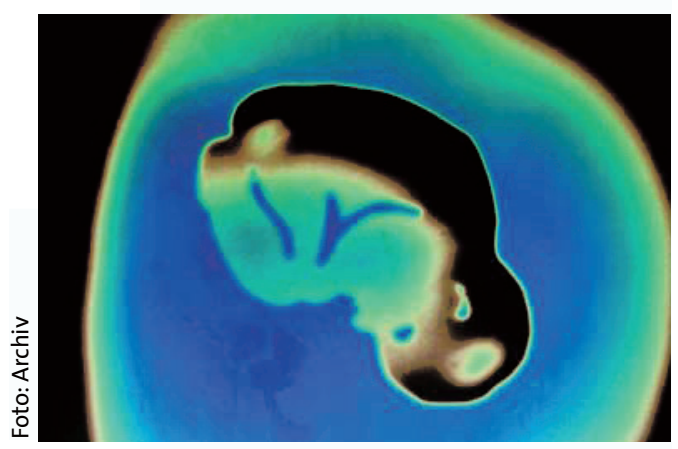

Armer Schlucker? Durch Ingestion von Amnionflüssigkeit kommt der fetale Magen-Darm-Trakt schon früh mit maternalem IgE in Kontakt

zeigte z. B. die Analyse von Chemokinund Chemokinrezeptorgenen anhand von CCR5-Varianten oder von Unterschieden in der Promoter-Region für RANTES. Als weiteren Gesichtspunkt nannte Nickel eine genetische Prägung von Abwehrmechanismen, die z. B. anhand einer unterschiedlichen Empfindlichkeit gegenüber Plasmodien-vermittelten Erkrankungen deutlich wird. Es existieren auch "Susceptibility Genes“, die eine Neigung zu entzündlichen Erkrankungen vermitteln. Weitere Vali- dierung benötigt auch die Aussage, dass die Neigung zur überschießenden Entzündungsantwort einen gemeinsamen genetischen Hintergrund für Psoriasis und atopische Erkrankungen bilden könnte.

\section{Maternofetale Interaktion}

In den 90er-Jahren ergaben sich erste Hinweise auf eine immunologische Interaktion zwischen Mutter und Kind: Als Beispiel nannte Cathy Jones, Southampton, England, eine erhöhte Ekzemund Asthma-Inzidenz bei Kindern mit hohem Nabelschnur-IgE. Die Bedeutung der von Godfrey et al. [Clin Exp Allergy 1994; 24: 641-8] sowie von Leadbitter und Mitarbeitern [Thorax 1999; 54: 905-10] gefundenen Korrelation zwischen großem Schädelumfang bei Geburt und erhöhtem späteren Serum-IgE-Wert ist noch unklar. Jones interpretiert die reduzierte In-vitro-IFN$\gamma$-Bildung und T-Zell-Proliferation bei Neugeborenen atopischer Mütter - angesichts der auch erniedrigten, durch Allergene induzierten IL-13-Produktion - als allgemeine „Down-Regulation“.

Zum Stillen als wichtigem postpartalen Faktor berichtete Jones, dass die Brustmilch atopischer Mütter höhere Spiegel an IL-4, IL-8 und RANTES enthielte. Über viele Monate gestillte Kinder atopischer Mütter hätten zunächst weniger, später jedoch gemäß Wright et al. [Thorax 2001; 56: 192-7] mehr atopische Erkrankungen entwickelt. Maternale Einflussfaktoren auf die kindliche Entwicklung während der Schwangerschaft wären laut Jones mütterliches IgE, Zytokine und lösliche Signale wie sCD14. Eine Assoziation zwischen niedrigen sCD14-Spiegeln in
Amnionflüssigkeit oder Brustmilch und erhöhter kindlicher Asthmainzidenz sei gefunden worden. Einige Studien hätten auch mütterliches IgE bereits ab der 13. Schwangerschaftswoche in der Amnionflüssigkeit nachgewiesen. Dr. Jones wies darauf hin, dass gerade durch Schlucken der fetale Magen-DarmTrakt IgE exponiert werde. Jones zeigte in der Immunhistologie fetaler Darmbiopsien häufig darstellbare CD23+ Zellen. Ihre Arbeitsgruppe untersucht derzeit, ob diese meist in der Nähe von Peyerschen Plaques darstellbaren Zellen mit Expression des niedrigaffinen IgERezeptors B-Lymphozyten oder dendritischen Zellen entsprechen. Zu diskutieren wäre eine IgE-vermittelte Antigen-Fokussierung oder ein Reifungssignal für den kindlichen Darm. Zusatzfaktoren kommen von der Plazenta, wie der immunhistologische Nachweis von IL-13-positiven Zellen und von TGF$\beta$-Produktion zeigt.

\section{Sensibilisierung in utero?}

Zur Frage einer Sensibilisierung in utero berichtete Zsolt Szepfalusi, Wien, über Untersuchungen des Nabelschnurblutes. Dabei spiegelt die In-vitro-Zellproliferation auf BSA und Ovalbumin eine Immunantwort bereits in der Fetalperiode wider. Kinder mit atopischen Erkrankungen haben initial eine niedrige IFN- $\gamma$ - sowie IL-4- und IL-5-Produktion in vitro. Zusätzlich seien Fel d1 und Der $\mathrm{p} 1$ schon in der Amnionflüssigkeit nachgewiesen worden. Szepfalusi berichtete über eigene Versuche am Modell konfluierender Trophoblastenkulturen, bei denen er gezeigt hat, dass Bet v 1 die Plazenta überwinden kann. Derzeit wird von Szepfalusi untersucht, ob Allergene an Plazentagewebe binden bzw. ob Serum allergischer Patienten etwa über Immunkomplexbildung eine veränderte Allergen-Plazentapassage bewirkt. Abschließend bemerkte Szepfalusi, dass Sensibilisierungen wohl bereits in utero stattfinden könnten, die Palette immunmodulierender Faktoren ist aber weitgehend unbekannt.

Priv.-Doz. Dr. P. Thomas, München

\footnotetext{
Hauptsymposium „Mother, fetus and infant interaction in the development of allergy“, Berlin 2001
} 